\title{
Chemodectoma of the orbit
}

\author{
A. AHMED, O. G. DODGE, AND R. S. KIRK \\ From the Departments of Pathology, Manchester University, and the Christie Hospital, Manchester
}

SYNOPSIS The histological and clinical features of a primary chemodectoma arising in the orbit are described. It is suggested that the tumour may have arisen from chemoreceptor tissue in the $\mathrm{N}_{\mathrm{N}}$ area of the lacrimal gland.

Tumours of the non-chromaffin paraganglia (chemodectomas) have a distinctive histological pattern. Beside the tumours arising from the known sites of non-chromaffin paraganglionic (chemoreceptor) tissue, tumours of similar appearance have been recorded at sites where such paraganglionic tissue is not certainly known to occur in man. We now report a chemodectoma arising in the orbit.

\section{CASE REPORT}

A retired farmer, aged 65 , presented with a swelling of the right lacrimal region, causing downward displacement of the eyeball. He had noticed this for a few months. Radiographs showed destruction of bone in the roof of the orbit, which was explored, and a lobulated tumour was found in relation to the lacrimal gland. It was fixed to the surrounding orbital tissues, and at its upper margin was in contact with the dura through the eroded bone. The tumour was removed piecemeal. It was highly vascular and haemorrhage was considerable. The histological findings are described below. Within three months the tumour had recurred (Fig. 1) and by this time radiographs showed extension of the destructive process in the roof of the orbit, and involvement of the lesser wing of the right sphenoid bone, the fronto-zygomatic process, and the frontal and ethmoid sinuses.

The patient received a course of radiation to the orbit (tumour dose 5,000 rads) but the tumour showed very little evidence of regression. Two months later the patient returned with pains in the right loin. The orbital lesion was not greatly changed, but a radiograph of the spine showed collapse of the body of the tenth thoracic vertebra, to which a single exposure of radiation was given. The patient returned home, and his condition gradually deteriorated. He developed severe headaches and finally went into coma in which he remained until his death two days later. No necropsy was performed. The total course from the first sign of a tumour to death was 10 months.

Received for publication 2 January 1969.

\section{HISTOPATHOLOGY}

The tumour was received in several fragments, fixed in $\frac{\mathbb{D}}{\mathrm{D}}$ $10 \%$ formalin. Sections were stained for reticulin, argentaffin and argyrophil material, and for mucins, as well as by the routine methods.

The tumour consisted of strands of cells separated by $\vec{\theta}$ a network of sinusoid-like channels (Fig. 2) which contained blood and were lined by a single layer of flattened endothelium (Fig. 3). The tumour cells lay in close apposition to the endothelium, and showed nuclear pleomorphism and prominent nucleoli (Fig. 4). Mitoses were infrequent. The abundant cytoplasm was granular and eosinophilic, although a few cells showed vacuolated $\mathbb{D}$ cytoplasm. The cell walls were moderately distinct.

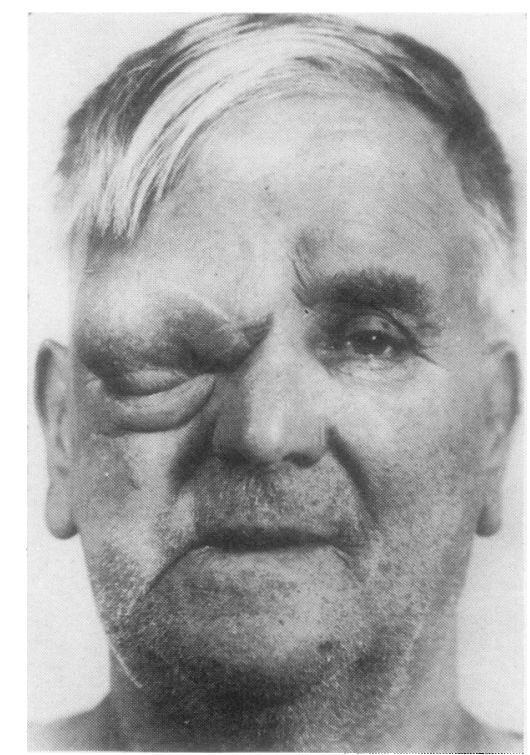

FIG. 1.

Recurrent

tumour dis-

placing eyeball downwards. The scar of the previous excision is visible. 


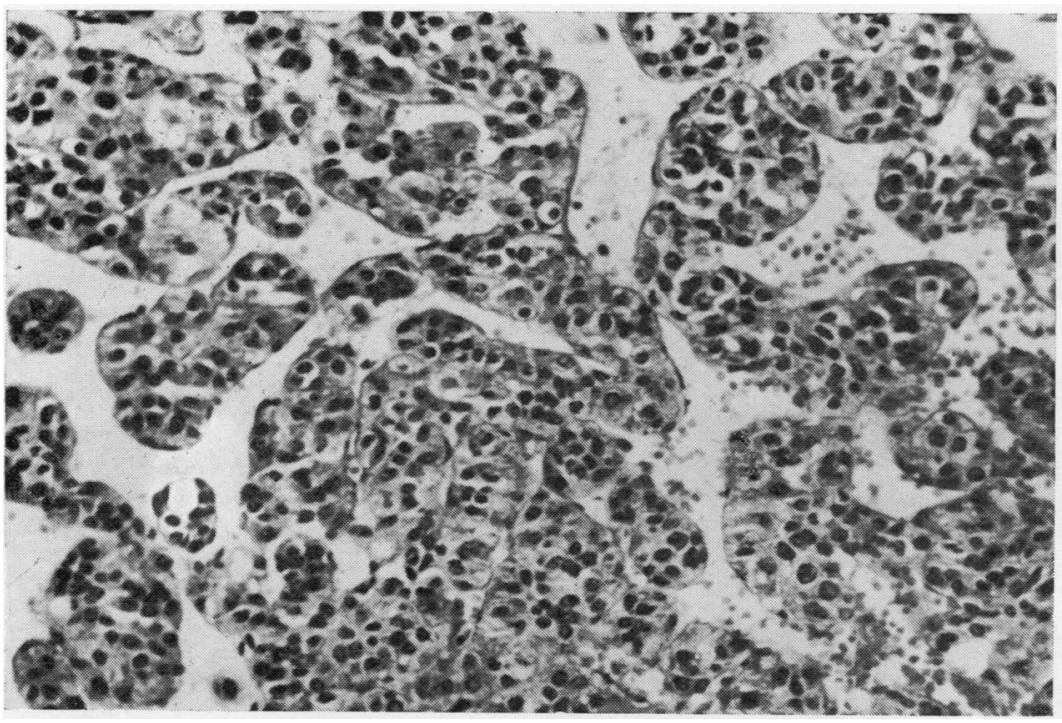

FIG. 2. General configuration of the tumour showing columns of cells between sinusoidal channels. Haematoxylin and eosin $\times 160$.

FIG. 3. Flat endothelial cells

lining the sinusoids, with

tumour cells in close apposition.

Haematoxylin and eosin $\times 640$.

FIG. 2.

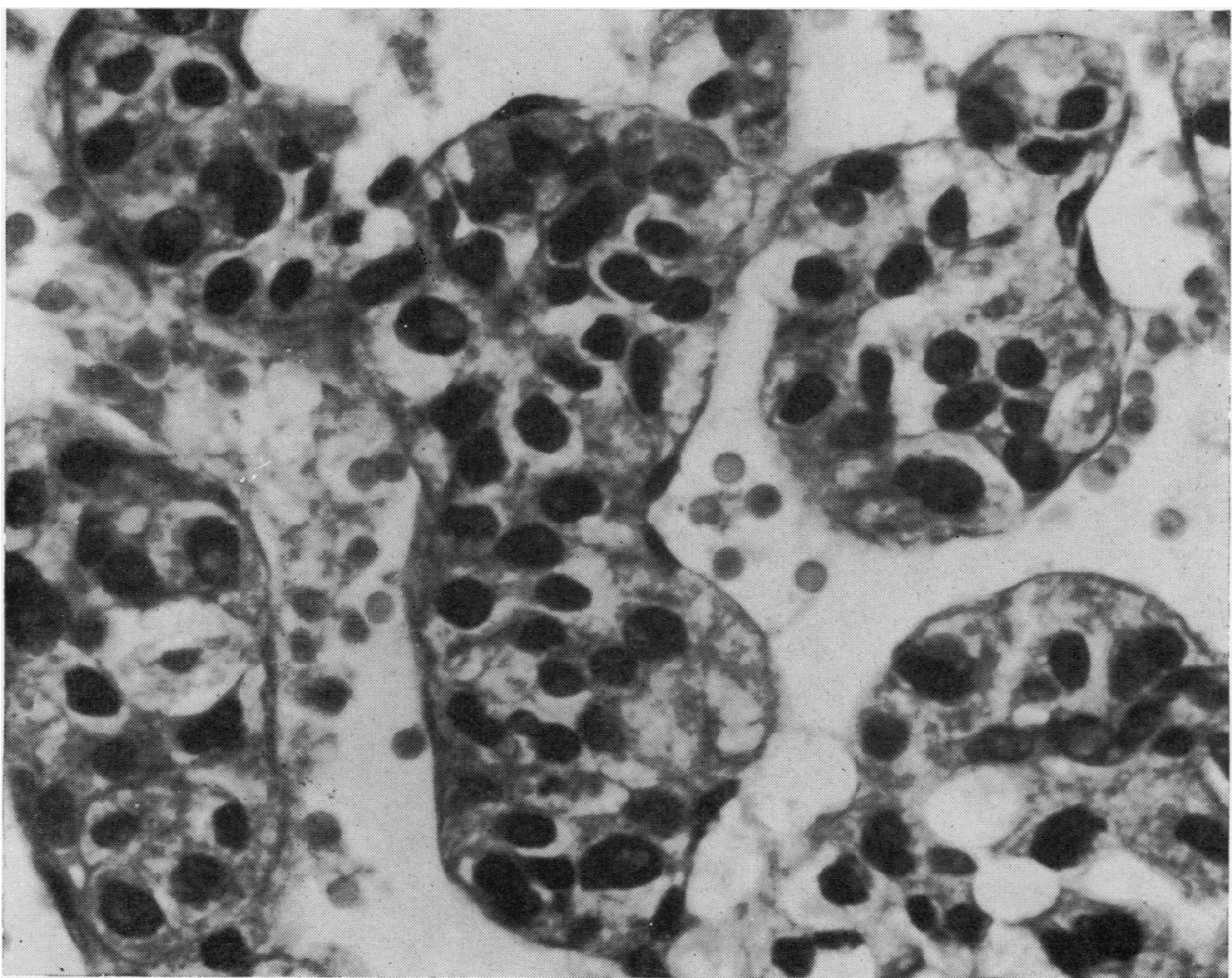

FIG. 3 . 


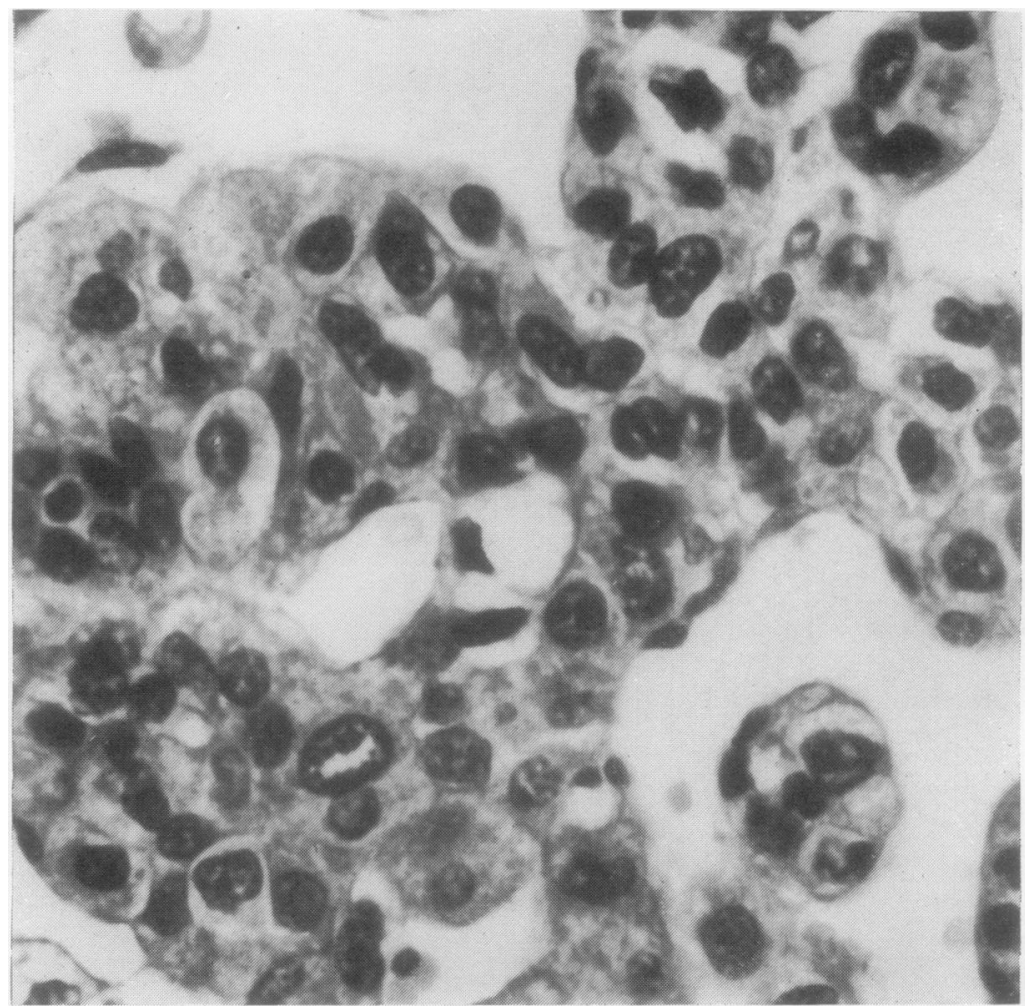

FIG. 4. Tumour cells showing granular cytoplasm and nuclear. pleomorphism. Haematoxyliñ and eosin $\times 640$.

FIG. 5. Silver impregnation? showing reticul in fibres en- N closing groups of cells and forming the basement mem- ir brane of the sinusoids. Reticulin $\times 400$.

FIG. 4.

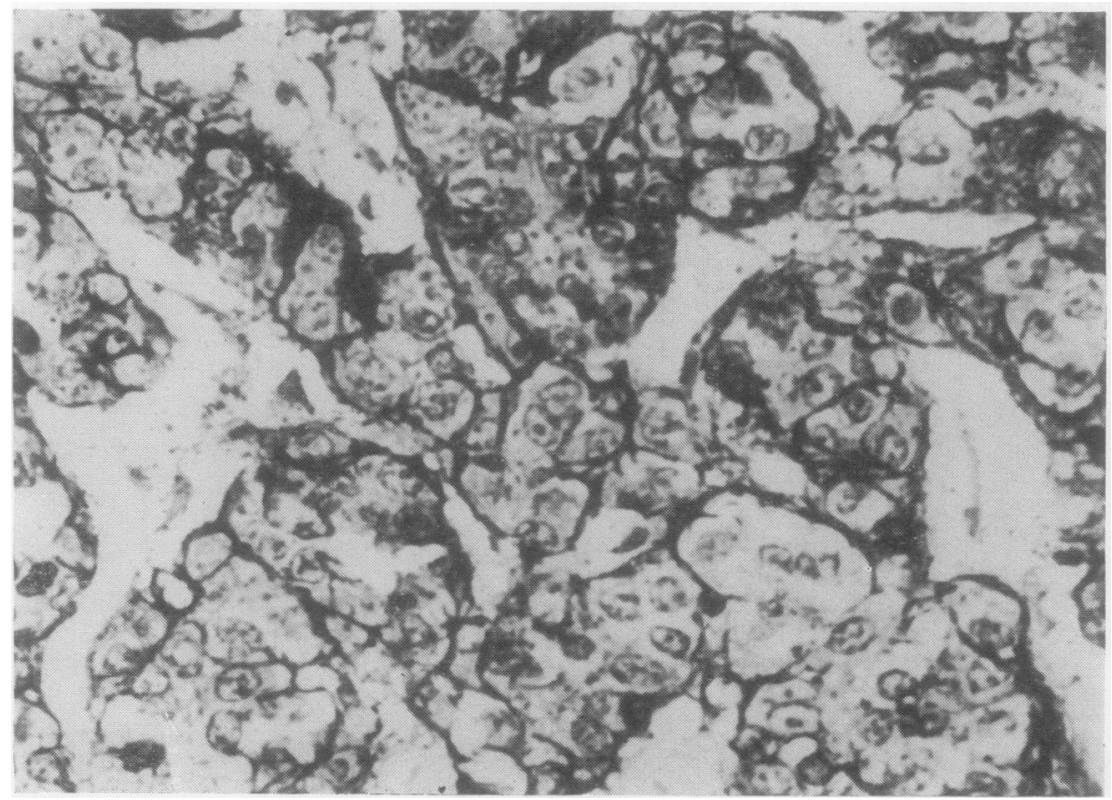

FIG. 5. 
Reticulin impregnation (Fig. 5) showed that fine reticulin fibres enclosed small groups of tumour cells, and also formed a basement membrane between the vessels and the tumour cells. No argentaffin or argyrophil granules were seen, and no mucin was demonstrated. The appearances were considered to be characteristic of a chemodectoma.

\section{DISCUSSION}

Tumours of the known chemoreceptor organs, such as the carotid body, aortic body, glomus jugulare, and ganglion nodosum, have long been familiar to pathologists (Lattes, 1950). Tumours of similar structure, and presumed to arise from chemoreceptor tissue, have been described in the retroperitoneum (Zacks, 1958), in the organ of Zuckerkandl (Cragg, 1934), and in the lungs (Heppleston, 1958; Fawcett and Husband, 1967). Nodules resembling chemodectomas were found by Spain (1967) in a survey of postmortem lungs. Most of the lungs showed evidence of thromboembolic disease, and Spain suggested that ischaemia might stimulate the growth of these nodules.

It is not definitely established that non-chromaffin paraganglionic tissue occurs in the human orbit. Botár and Pribék (1935) described a nodule of paraganglionic tissue, near the ciliary ganglion, in the orbit of the chimpanzee, and Mawas (1936) described, but did not illustrate, paraganglionic tissue in the orbit of the human newborn. This tissue was situated in the infero-lateral part of the orbit, close to the eyeball, between the inferior and external rectus muscles, and Mawas called it the infra-orbital paraganglion'. On the other hand, Fisher and Hazard (1952) were unable to find any paraganglionic tissue in the serially sectioned retrobulbar tissues of the orbit. Their dissection, however, may not have included the area of the lacrimal gland.

There have been a few previous reports of chemodectomas in the orbit. The earliest case is probably the retrobulbar tumour reported by Hughes and Ambrose (1944) as an 'adrenal rest tumour'. The photomicrographs show what may well have been a chemodectoma. Fisher and Hazard (1952) described a chemodectoma in the superolateral region of the orbit, but their photomicrographs are not altogether convincing, an opinion shared by Lattes, McDonald, and Sproul (1954). These authors recorded a chemodectoma in the lateral portion of the right orbit in a patient who also had a carotid-body tumour. The two tumours were histologically similar. Since nonchromaffin paragangliomas were already known to occur multicentrically (Lattes, 1950) it was thought that the orbital tumour could be a primary tumour arising, perhaps, in the 'paraganglion ciliare' of Botár and Pribék (1935).
Subsequently, Tye (1961) reported a non-chromaffin paraganglioma arising in the lateral rectus muscle of a 4-year-old boy, and Nirankari et al (1963) described what appears to have been a malignant non-chromaffin paraganglioma, arising in the outer half of the orbit, which recurred in the lower eyelid.

In the present case, the tumour was centred in the anterior part of the orbit and the initial clinical diagnosis was that of a mucus-retention cyst of the lacrimal gland. The surgical excision presented a difficult problem because the tumour was highly vascular, it was fixed to the orbital structures, and it had eroded the bony roof of the orbit.

The behaviour of chemodectomas is notoriously difficult to predict from the histological pattern. Although the present tumour did not show the histological features of frank malignancy, there seems no doubt that it behaved from the start as an aggressively infiltrating tumour, and the radiological evidence indicates that the tumour did not only cause extensive local bone destruction but also metastasized to a thoracic vertebra. Death is likely to have been due to meningitis following exposure of the dura by the tumour. The chemodectomas are not radiosensitive tumours, and in this case postoperative radiotherapy did not produce any very noticeable effect on the tumour.

The discovery of chemodectomas has in the past suggested the presence of non-chromaffin paraganglionic tissue at various sites unrecorded by anatomists. Two possible sites of orbital paraganglionic tissue have been suggested: one in the area of the ciliary ganglion (Botár and Pribék, 1935) and the other below the eyeball (Mawas, 1936). However, the examples of orbital chemodectoma so far described have all arisen in the lateral or superolateral portion of the orbit. This suggests that paraganglionic tissue is present in this region of the orbit, possibly adjacent to the lacrimal gland.

We are grateful to Mr K. Harrison for the clinical details of this case, to Professor R. E. Coupland for references to orbital paraganglia, and to $\mathrm{Mr} \mathrm{R}$. Schofield (Medical Illustration Unit, Christie Hospital) for Figure 1.

\section{REFERENCES}

Botár, J., and Pribék, L. (1935). Ann. Anat. path., 12, 227.

Cragg, R. W. (1934). Arch. Path., 18, 635.

Fawcett, F. J., and Husband, E. M. (1967). J. clin. Path., 20, 260.

Fisher, E. R., and Hazard, J. B. (1952). Cancer (Philad.), 5, 521.

Heppleston, A. G. (1958). J. Path. Bact., 75, 461.

Hughes, L. W., and Ambrose, A. (1944). J. Amer. med. Ass., 126, 231 Lattes, R. (1950). Cancer (Philad.), 3, 667.

-, McDonald, J. J., and Sproul, E. (1954). Ann. Surg., 139, 382. Mawas, J. (1936). C.R. Acad. Sci. (Paris), 202, 977.

Nirankari, M. S., Greer, C. H., and Chaddan, M. R. (1963). Brit. J. Ophthal., 47, 357. 
Spain, D. M. (1967). Amer. Rev. resp. Dis., 96, 1158.

Tye, A. A. (1961). Trans ophthal. Soc. Aust., 21, 113.

Zacks, S. I. (1958). Amer. J. Path., 34, 293.

\section{ADDENDUM}

Since this paper was accepted for publication,
Thacker and Duckworth (Cancer, 1969, 23, 1233) have reported another orbital chemodectoma, in axp? 55-year-old woman. They emphasize the difficultyo in predicting the behaviour of these tumours frome the histological pattern. 